Indian J. Anim. HIth. (2018), 57(1) : 99-102

Short Communication

\title{
ASCITES OF HEPATO-CARDIAC ORIGIN IN A LABRADOR RETRIEVER DOG
}

\author{
C. Sen, A. MAJie, J. MuKherJeE*, D. GHOSH ${ }^{1}$, P. MuKherJeE ${ }^{1}$ \\ S. S. KESH ${ }^{2}$, S. CHAUDHURY AND P. K. DAS \\ Department of Veterinary Physiology \\ Faculty of Veterinary and Animal Sciences \\ West Bengal University of Animal and Fishery Sciences \\ Kolkata-700 037, West Bengal, India
}

\begin{abstract}
The present study describes the diagnosis of an ascites of hepato-cardiac origin in a two year old Labrador Retriever bitch. The animal was suffering from chronic cough and recurrent ascites for more than six months. The physical examination revealed ascites which was confirmed through ultrasonography along with hepatic cyst. All the hemato-biochemical reports were found normal except TLC. Upon electrocardiography, it was revealed biphasic QRS comples (rS), widening of $S$ wave and right axis deviation suggestive of right bundle branch block.
\end{abstract}

Key word: Ascites, Bundle branch block, ECG, Ultrasonography

A two years old, female, Labrador Retriever dog was presented to the clinic with the history of chronic cough (tachypnea, respiratory rate 45 breaths per minute), exercise intolerance along with recurrent ascites since last six months. Upon physical examination it was for ascites. Radiograph showed hepatomegaly.

\footnotetext{
*Corresponding author

${ }^{1}$ Department of Veterinary Surgery and Radiology, WBUAFS, Kolkata

${ }^{2}$ Department of VCC, WBUAFS, Mohanpur, Nadia
} 
The animal exhibited normal hemogram viz. haemoglobin $13.6 \mathrm{gm} \%$, packed cell volume $41.8 \%$, total erythrocyte count $6.16 \times 10^{6} /$ $\mathrm{mm}^{3}$, total leukocyte count $15.2 \times 10^{3} / \mathrm{mm}^{3}$, neutrophil $63 \%$, lymphocyte $31 \%$, eosinophil $02 \%$, and monocyte $04 \%$ and platelet counts $25 \times 10^{5} / \mathrm{mm}^{3}$. All the erythrocyte indices were also within normal range.

Serum biochemistry showed blood glucose $80 \mathrm{mg} / \mathrm{dL}$ (random), total protein $7.32 \mathrm{gm} /$ dL with albumin: globulin ratio of 0.73 . Liver function test appeared normal with total bilirubin $0.19 \mathrm{mg} / \mathrm{dL}$, bilirubin-direct $0.13 \mathrm{mg} / \mathrm{dL}$, bilirubin-indirect $0.06 \mathrm{mg} / \mathrm{dL}$, SGPT 50.2 IU/L, SGOT 49.3 IU/L and ALP 89.2 IU/L. The kidney function test also showed normal (creatinine $0.82 \mathrm{mg} / \mathrm{dL}$, uric acid $0.93 \mathrm{mg} / \mathrm{dL}$ ) with higher blood urea $37.0 \mathrm{mg} / \mathrm{dL}$.

Blood electrolyte profile showed sodium $142.0 \mathrm{mEq} / \mathrm{L}$, potassium $5.0 \mathrm{mEq} / \mathrm{L}$ and chloride $109.0 \mathrm{mEq} / \mathrm{L}$.

In ultrasonography, anechoic free fluid in the abdomen with floating viscera was appreciated (Fig. 1). The kidneys appeared normal with normal size and shape (left kidney, $4.9 \mathrm{~cm} \times 3.2 \mathrm{~cm}$ and right kidney, $5.6 \mathrm{~cm} \times 3.4 \mathrm{~cm}$ ) with clear corticomedullary demarcation. Urinary bladder showed normal without any rupture, uroliths or neoplasia. The liver showed normal echogenicity with hepatomegaly indicated as round edged hepatic lobes. A hepatic cyst $(2.7 \mathrm{~cm} \times 2.4 \mathrm{~cm})$ was also appreciated (Fig. 2).

The ECG (Lead-II) showed bi phasic QRS complex (rS), widening of S wave (Fig. 3). The equilateral triangle measurement system (Spasojevic-Kosic, 2011) using QRS complex of Lead I and Lead III was employed to determine the MEA and it was found that there was right axis deviation suggestive of right bundle branch block.

As the animal was diagnosed with ascites of hepato - cardiac origin, the animal was treated with enalapril @ $0.5 \mathrm{mg} / \mathrm{kg}$ body weight, orally bid, furosemide @ $4 \mathrm{mg} / \mathrm{kg}$ body weight, orally, bid and liver tonic. However after 3 months of treatment the animal was still suffering and prognosis is grave.

The aetiology of ascites in dogs may be of hepatic (Pradhan et al., 2008), renal (Peden and Zenoble, 1982) or cardiac origin (Kumar and Srikala, 2014; Mukherjee et al., 2017). The higher TLC in ascites in this study was in accordance with earlier reports of (Pradhan et al., 2008). In this case, the animal had normal kidney function profiles. So, the renal involvement in ascites can be ruled out. Cardiac origin ascites were associated with cardiomyopathy (Peden and Zenoble, 1982), right heart failure (Kumar and Srikala, 2014) 
Indian Journal of Animal Health, June, 2018

Ascites of hepato-cardiac origin in dog

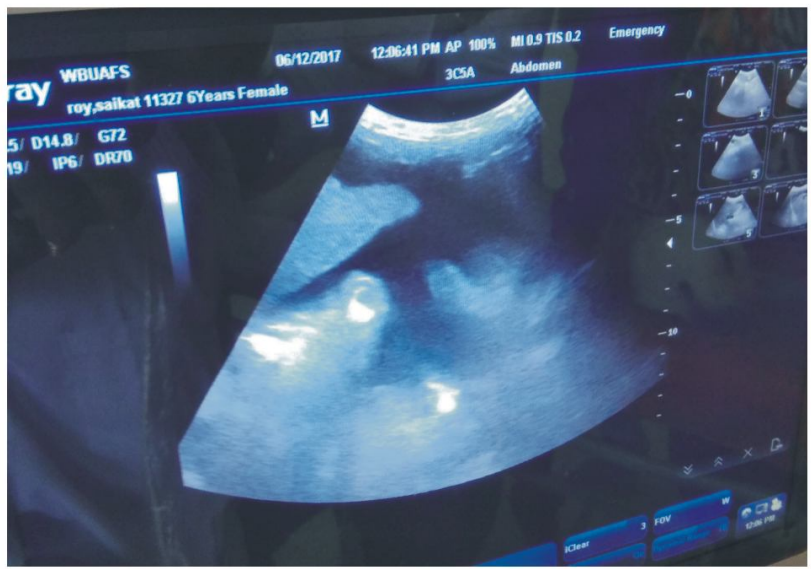

Fig. 1. Sonograph showing anechoic free fluid with floating viscera

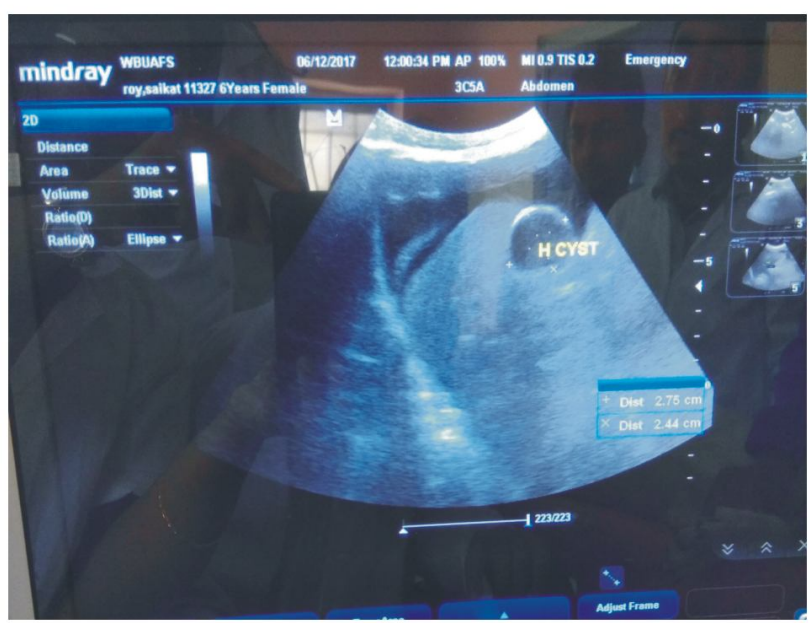

Fig. 2. Sonograph showing hepatic cyst

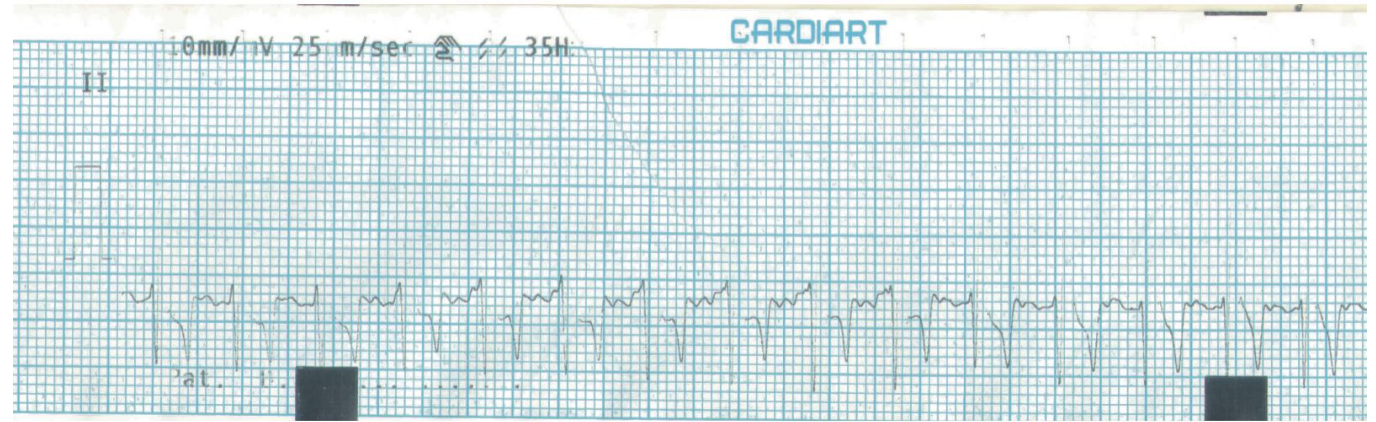

Fig. 3. ECG showed biphasic QRS complex (lead-II) 
or myocardial ischaemia (Mukherjee et al., 2017). The appearance of bi-phasic QRS complex (rS) with low amplitude $\mathrm{R}$ wave along with widening of $S$ wave in ECG was suggestive of right bundle branch block (Leininger, 1984; Tilley and Burtnick, 1999). Leininger (1984) also reported right axis deviation as in our findings. The pathogenesis of ascites due to right heart failure was reviewed by Peden and Zenoble (1982). They stated that right heart failure causes portal hypertension and escape of plasma proteins into the interstitial space of

\section{REFERENCES}

Kumar KS and Srikala D, 2014. Diagnosis and management of cholecystitis in dogs. Int J Agric Sc Vet Med, 2(3): 13-15

Leininger SR, 1984. Right bundle-branch block in a dog. Mod Vet Pract, 65(1): 33,36

Mukherjee P, Mukherjee J, Kesh SS and Das
Disse from the sinusoidal capillaries. Leakage of plasma proteins increases the hydrostatic pressure and the fluids accumulate in the abdominal cavity.

Conflict of Interests: The authors declare there is no conflict of interests amongst them.

\section{ACKNOWLEDGEMENT}

Authors are extremely grateful to the ViceChancellor, WBUAFS for providing financial support to complete the study.
PK, 2017. Ascites of cardiac origin in a dog - a case study. Indian $\mathbf{J}$ Anim Hlth, 56(1) : 111-112

Peden WM and Zenoble RD, 1982. Canine Ascites. IOWA state university (Digital repository, article 3), 44(1): 12-17

Pradhan MS, Dakshinkar NP, Waghaye UG 
and Bodkhe AM, 2008. Successful treatment of ascites of hepatic origin in dog. Vet World, 1(1): 23

Spasojevic-Kosic LJ, 2011. Comparison of two methods in the determination of hearts mean electric axis in dogs.
Savremena Poljoprivreda, 60: 190-194

Tilley LP and Burtnicl NL, 1999. Electrocardiography for Small Animal Practtisoner. Teton New Media publication, USA (ISBN 9781893441002), pp 84 